\title{
Editorial
}

\section{The new face of the Brazilian Journal of Morphology}

\author{
Valéria Paula Sassoli Fazan ${ }^{1}$ \\ ${ }^{1}$ Department of Surgery and Anatomy, School of Medicine of Ribeirão \\ Preto, Universidade de São Paulo, Brazil \\ J Morphol Sci 2019;36:1.
}

Dear authors and readers,

The Journal of Morphological Sciences is facing changes on the editorial board to accomplish the international demands for higher indexations of the journal. This is a challenge for the new editorial board that will follow the new trends in science publications preserving the peer review process and keeping up with the high quality of the published manuscripts.

Editors and editorial board members were chosen based on criteria including not only the high standard scientific indexes and specific areas of expertise, but also the strong will of working hard to improve the Journal of Morphological Sciences in many different ways. We understand the importance of morphology as the foundation for the further understanding of several other biological and bio-

medical sciences, and we will work to keep the morphological sciences stronger as other sciences develop together with us.

We will broaden the areas of interest of the Journal of Morphological Sciences, and manuscripts dealing with imaging, neurosciences, locomotor system, dental anatomy, veterinary pathology, and histology will be strongly encouraged. We will continue to encourage publications on structure, functional morphology, animal development, as well as all levels of structural organization, from the submicroscopic to the macroscopic levels.

Finally, but most important, we would like to thank the herculean job done by the previous editors, together with the editorial board, who worked very hard to keep our journal running well and smoothly up to date.

Address for correspondence Valéria Paula Sassoli Fazan, MD, PhD, Departamento de Cirurgia e Anatomia, Escola de Medicina de Ribeirão Preto, Universidade de São Paulo, Av. dos Bandeirantes 3900, Monte Alegre, Ribeirão Preto, SP, 14049-900, Brazil (e-mail: vpsfazan@yahoo.com.br).
DOI https://doi.org/

10.1055/s-0039-1683988.

ISSN 2177-0298.
Valéria Paula Sassoli Fazan, MD, PhD

Editor-in-Chief Journal of Morphological Sciences

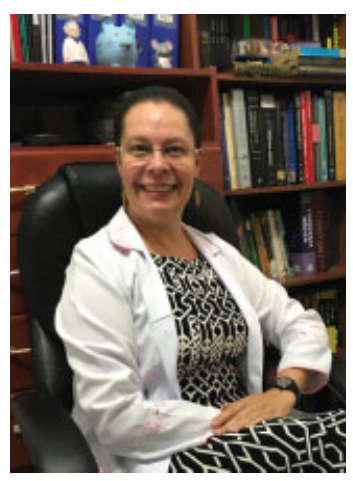

Copyright $\odot 2019$ by Thieme Revinter Publicações Ltda, Rio de Janeiro, Brazil
License terms

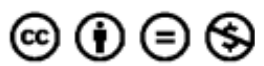

